Review

\title{
Spin catalysts: A quantum trigger for chemical reactions
}

\author{
Oleksiy V. Khavryuchenko a,\#, Volodymyr D. Khavryuchenko a, Dangsheng Su b,c,* \\ a Computation Chemistry Group, Revutskogo Str. 13, App. 149, Kyiv UA-02091, Ukraine \\ b Shenyang National Laboratory for Materials Science, Institute of Metal Research, Chinese Academy of Science, Shenyang 110016, Liaoning, China \\ ' Department of Inorganic Chemistry, Fritz Haber Institute of the Max Planck Society, Faradayweg 4-6, D-14195 Berlin, Germany
}

A R T I C L E I N F O

Article history:

Received 15 April 2015

Accepted 28 June 2015

Published 20 October 2015

Keywords:

Catalysis

Spin chemistry

Homolytic bond cleavage

Oxidative processes

Radicals coupling

\section{A B S T R A C T}

Spin catalysis allows restrictions of the spin conservation rule to be overcome, and, moreover, provides a tool for fine control of elementary reactions. Spin-conductive solid catalysts make processes over surfaces strongly correlated and also can trigger the direction of the reaction via external magnetic field application. Activation/deactivation of $\mathrm{O}_{2}$ and non-polar small molecules, homolytic bond cleavage, and coupling of radicals are within the practical scope of spin catalysis.

(C) 2015, Dalian Institute of Chemical Physics, Chinese Academy of Sciences. Published by Elsevier B.V. All rights reserved.

\section{Introduction}

Catalysis is usually considered in terms of the energy difference between initial and transition states to increase the rate of reaction required to either enable an alternative reaction pathway with a lower energy transition state to occur or increase the energy of the initial state of the reagents, e.g., by changing the solvent or adsorbing molecules on a specific surface. However, in certain classes of reactions, this might not be sufficient because the reagents and products possess different spin states, and the spin conservation rule formally prohibits such processes (e.g., formation of water from $\mathrm{H}_{2}$ and $\mathrm{O}_{2}$, oxidation of $\mathrm{NO}$, and oxidative complexation of $\mathrm{Co}^{3+}$. Even overcoming the energetic barrier, the system cannot resolve into stable products without change of the electronic spin multiplicity state. Such reactions can still occur, but they require specific non-thermodynamic conditions. Usually, they are referred to as processes where spin is not conserved.
The most straightforward way to change the electronic spin of a system is a spin-flip of an electron by interaction with the spin of the atom nucleus. This event is realized through spin-orbital coupling, and thus its probability strictly depends on the atomic number of the element. Starting from $3 d$ metals, it might occur even more frequently because of higher coupling efficiency with $d$ orbitals, so spin-crossing is a conventional way to explain why spin-forbidden reactions take place. However, the probability of spin flipping of light atoms is negligible (for hydrogen it is of the order of 10-15 s-1). Thus, when considering metal-free chemistry, one should consider the second way of spin prohibition rule cancellation: spin catalysis, which is not related to interaction of the unpaired electron with particles within an atom.

Spin catalysis is defined as "phenomena in which chemical reactions are promoted by substances which assist in overcoming spin-prohibition or in which the activation barrier is lowered through spin uncoupling induced by a paramagnetic

\footnotetext{
* Corresponding author. Tel: +86-24-23971577; Fax: +86-24-83970019; E-mail: dssu@imr.ac.cn

\# Corresponding author. Tel: +38-044-5637135; Fax: +38-044-5634274; E-mail: alexkhavr@gmail.com

DOI: 10.1016/S1872-2067(15)60948-2 | http://www.sciencedirect.com/science/journal/18722067 | Chin. J. Catal., Vol. 36, No. 10, October 2015
} 
catalyst" [1]. More simply, to obtain the desired (and more thermodynamically favorable) spin state, one of the reacting particles can exchange its magnetic moment with the third body (spin catalyst), which presumably has pseudo-spin-degenerate ground or low-lying excited states. Thus, the overall spin state of the system is still conserved but the reaction can proceed (Fig. 1).

It should be emphasized that the spin catalyst term might indicate both molecular and solid states, with the latter often being much more convenient for industrial application.

\section{Basics of spin catalysis}

Historically, spin catalysis has been investigated in the paradigm of spin chemistry concurrently with chemically induced dynamic nuclear polarization and reactions in external magnetic fields, mainly for processes in solution, and investigated by electron paramagnetic resonance spectroscopy. The theory of such processes can be found in the works of Buchachenko, Minaev, and Schwarz [2-5]. Only brief excerpts are given here.

First, we will discuss a radical pair in the gas phase. It is obvious that the pair can recombine to form a covalent bond only in the singlet state (i.e., in the case when the spins of the radicals are opposite). The probability of such a collision is $25 \%$ because two radicals can equiprobably form one singlet and three triplet states, with the latter being anti-bonding. Howev$\mathrm{er}$, in the case of the presence of a third radical (spin catalyst), one of the triplet states $\left({ }^{1} T\right)$ can turn into a reactive singlet $\left({ }^{1} S\right)$ through spin-spin interaction with $\mathrm{R}_{3}$, with the probability of this process exponentially decreasing with increasing distance between the interacting radicals. It should be noted that to make spin catalysis effective, the values of the spin-spin interactions in the $\mathrm{R}_{1}-\mathrm{R}_{3}$ and $\mathrm{R}_{2}-\mathrm{R}_{3}$ pairs should be different, which can be realized either by the different nature of the interacting radicals $R_{1}$ and $R_{2}$ (e.g., different spin-centering atoms) or different distances $d\left(\mathrm{R}_{1}-\mathrm{R}_{3}\right)$ and $d\left(\mathrm{R}_{2}-\mathrm{R}_{3}\right)$ (Fig. 1(b)).

The equilibrium of the $R_{A}-R_{B}$ radical pair in dilute media is shown in Scheme 1. For covalent bond homolytic cleavage, constant $k_{1}$ is much larger than $k-1$, so the overall rate is mostly controlled by diffusion step 2 . Singlet-triplet transformation is formally forbidden because of the spin conservation rule and depends on the probability of the spin flip, which is extremely

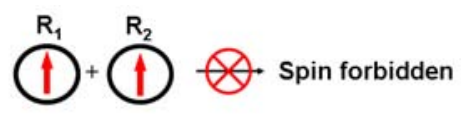

(a)
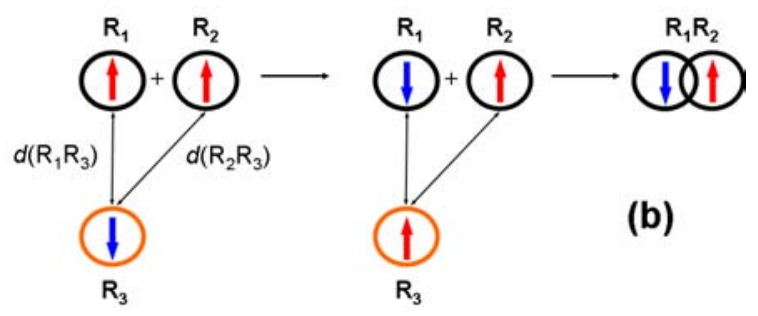

Fig. 1. (a) Spin-forbidden elementary reaction of a radical pair. (b) Radical $R_{3}$ catalyses recombination of radicals $R_{1}$ and $R_{2}$ via spin-spin interaction with $R_{1}$ (because of the shorter distance between $R_{1}$ and $R_{3}$ ).

$$
\begin{aligned}
& \left.\mathrm{M} \stackrel{k_{1}}{\rightleftarrows} 1 \mathrm{R}_{\mathrm{A}}+\mathrm{R}_{\mathrm{B}}\right) \stackrel{k_{2}}{\rightarrow} \mathrm{R}_{\mathrm{A}}+\mathrm{R}_{\mathrm{B}}(\mathbf{a}) \quad{ }^{2}\left(\mathrm{M}+\mathrm{R}_{\mathrm{D}}\right) \stackrel{k_{1}}{\stackrel{2}{\rightleftarrows}}{ }^{2}\left({ }^{1}\left(\mathrm{R}_{\mathrm{A}} \mathrm{R}_{\mathrm{B}}\right)+\mathrm{R}_{\mathrm{D}}\right) \stackrel{k_{2}}{\rightarrow} \mathrm{R}_{\mathrm{A}}+\mathrm{R}_{\mathrm{B}}+\mathrm{R}_{\mathrm{D}} \quad \text { (b) } \\
& k_{-1} \quad k_{-3} \uparrow \downarrow k_{3} \quad k_{4} / \\
& { }^{3}\left(\mathrm{R}_{\mathrm{A}}+\mathrm{R}_{\mathrm{B}}\right) \\
& \left\{{ }^{2}\left({ }^{3}\left(R_{\mathrm{A}} \mathrm{R}_{\mathrm{B}}\right)+\mathrm{R}_{\mathrm{D}}\right),{ }^{4}\left({ }^{3}\left(\mathrm{R}_{\mathrm{A}} \mathrm{R}_{\mathrm{B}}\right)+\mathrm{R}_{\mathrm{D}}\right)\right\}
\end{aligned}
$$

Scheme 1. (a) Equilibrium of the $R_{A}-R_{B}$ radical pair. (b) Equilibrium of the radical pair in the presence of paramagnetic admixture $R_{D}$ (spin catalyst). Adapted from Selihov's lectures on spin chemistry [6].

improbable. Hence, this stage is the subject of spin catalysis, which opens the possibility of reaction 3 , so that overall rate of the reaction comprises diffusion of both singlet $\left(k_{2}\right)$ and triplet $\left(k_{4}\right)$ radical pairs (Scheme $1(\mathrm{~b})$ ). The probability of interaction between the radical pair and the paramagnetic admixture can be estimated by the Smoluchowski equation. The reverse reaction can be described with a similar set of equations, so it is clear that the elementary reactions of the recombination of radicals and covalent bond homolytic cleavage are both spin catalysis phenomena, because they enable additional reaction pathways to form the singlet or triplet radical pair, respectively [7-9]. However, the opposite direction of the processes might require different catalysts.

\section{Requirements for the spin catalyst}

It should be emphasized that there is no opposition between conventional catalysis and spin catalysis, and the same material can serve as both a conventional catalyst and a spin catalyst, decreasing the barrier of the reaction and providing a radical center for spin-exchange (examples will be discussed below). Moreover, a lot of modern materials combine classical and spin-catalyst properties, although this has never been emphasized. Some processes in nature occurring at polynuclear magnetic metalo-centers also might combine the effects of conventional catalysis (by activation of substrates), spin-crossing (owing to interaction with $d$ metals), and spin catalysis (owing to low-energy ferromagnetic-antiferromagnetic transitions in metal-oxide clusters) [10-14].

The main problem for practical implementation of spin catalysis in the gas phase is rather trivial: the probability of three-particle collision is low in dilute systems. In this regard, catalysis by solids has a number of advantages. First, the requirements for the solid to be a spin catalyst have to be defined:

(1) Active centers should have a small energy difference between at least two spin states (e.g., singlet and triplet). Presumably, this difference should be less than the energy of thermal motion at the temperature of the process.

(2) The solid should have high specific surface area (this coincides with the requirements for conventional heterogeneous catalysts).

(3) Optionally, the materials should be spin-conductive (i.e., spin centers should be conjugated and thus have a common electronic system). Although this requirement is not obligatory, it can give the catalyst valuable additional properties, as will be shown below.

We will now discuss the role that each of the above-mentioned criteria plays in the efficiency of the spin catalyst. Isolated free radicals in the absence of an external magnetic field 
are spin-degenerate by default. However, this does not apply for complex spin centers, like polynuclear complexes of paramagnetic $d$-metal ions, which often tend to have antiferromagnetic ordering. However, if the energy difference between the antiferromagnetic (ground) and ferromagnetic (excited) states is small, there should be no requirement for additional energetic activation of the spin catalyst to be able to exchange spin with one of the reacting species. Certainly, the lower this difference, the larger the partition of states for spin catalysis in each moment of time because of the Boltzmann distribution.

A large specific surface area allows more spin centers to be available for the interaction, similar to conventional heterogeneous catalysts. Additionally, adsorption of reagents specifically orients them relative to the spin catalyst, so the distance between different atoms in the substrate and the spin catalyst is more or less defined (Fig. 2), and thus the effect of spin catalysis is less stochastic.

In the previous cases, we considered only localized effects of the spin catalyst. However, what happens if a material is spin-conductive? The spin centers are then conjugated and have a common electronic system, so they are correlated (only the limit of the speed of light and possible defects in the structure hinder conductivity). This means that all of the species in the gas of liquid phase that are close to the surface of the catalyst particle are also correlated via the electronic system of the catalyst. If something happens to the catalyst (e.g., it is charged either positively or negatively, excited or quenched, becomes radical or diamagnetic) all of the species within the effective distance from the surface of the particle (which is still defined by the exponential law) are affected. In this case, the probability of the spin-spin interaction, which is a crucial factor for spin catalysis, greatly increases because there is no need for three-particle collision. The radicals can then exchange their spins via the electronic system of the catalyst when they are separated by large distances (up to hundreds of micrometers as long as the spin catalyst retains conductivity at such a range) (Fig. 2(d)).

Spin conductivity of the catalyst (or support) also provides the possibility to remotely control the charge and spin state of the catalytic centers through application of an external electric or magnetic field. The main problem of reactions in a magnetic
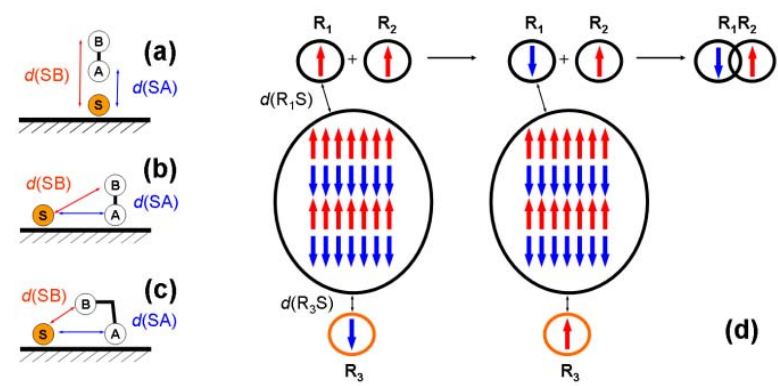

Fig. 2. Spin catalysis on a surface. (a) Spin catalyst is an adsorption center. (b,c) Spin catalyst is not an adsorption center. It can activate either atom A or B depending on the geometrical configuration of the adsorbed molecule. (d) Spin-conductive catalyst can correlate processes between spatially separate species (radical pair $\mathrm{R}_{1}-\mathrm{R}_{2}$ and radical $\mathrm{R}_{3}$ ) field is that the reacting system should be placed into the cavity of a strong magnet to induce different population of the spin levels [15]. Using a conductive support, it might be possible to separate the place of magnetic field application and the reaction space, and also to tune the material of the support to be more susceptible to the effect of the magnetic field. Hence, in this way, non-thermodynamic control over the reaction is possible by choosing appropriate external field parameters.

Conventional conductors, i.e., metals, possess the properties of a spin catalyst by default if an electric current (being a combination of two coherent spin currents) is running through them. This shows the peculiarities of electrocatalysis, which also can be explained by taking the spin-related properties of the catalyst and substrates into consideration.

\section{Possible practical applications}

For application of spin catalysis in real processes, a few points should be stressed. First, a lot of processes in nature and industry already apply this phenomenon (the most important example is combustion, where triplet $\mathrm{O}_{2}$ molecules convert into singlet products). Second, spin catalysis might have as many problems as benefits, for instance, initiating undesired chain radical reactions. The aim is to determine the right way to enable the target processes and suppress unwanted processes. Third, spin inhibition (cancellation of spin-changing reactions by introducing spin scavengers) might be as useful as spin catalysis. Fourth, spin catalysis/inhibition can be stimulated not only by the concentration of the magnetic particles (molecular radicals or paramagnetic solids), but also by external physical effects, such as magnetic and electric fields, and current (particularly, spin-polarized current), because there are both theoretical and experimental reports of their effect on the energy of the transition states and them "triggering" different reaction pathways [16-25].

Spin catalysis in homogeneous media (by soluble or volatile species) has been intensively studied [26]. We can refer to such applications as initiation and inhibition of radical polymerization (in rubbers, foams, glues, etc). Hereafter, we focus on application of spin catalysis in heterogeneous systems. Several areas of application can be proposed, each requiring more detailed investigation. Below each of these areas will be briefly discussed.

\subsection{Combustion}

A lot of effort has been made to develop effective catalysts to both prevent (in selective oxidation) and promote combustion (e.g., in removal of volatile pollutants). One of the main factors is the reactivity of the triplet (ground state) ${ }^{3} \mathrm{O}_{2}$ molecule, because the final products (and semi-products) of its reaction are usually singlet state, so changing the spin state of the system is often a limiting step. It should be noted that the complicated character of the elementary processes occurring during combustion is usually because of the necessity to deal with the spin conservation rule, leading to detours in the pathways of the reactions. One way to enhance the reactivity of dioxygen, apart 
from activating it by increasing its energy, is transformation into the singlet state (Fig. 3, top left), which is known to be one of the most forbidden transitions in nature [27]. By finding an appropriate spin catalyst, this transition can be either inhibited or prohibited (for instance, by introducing more effective spin scavenger), depending on the demands of the process.

\subsection{Mild oxidation}

Many industrial processes require mild oxidation of the reagent, e.g., oxidation of hydrocarbons to alcohols (with methane-to-methanol conversion being the most difficult) [28]. Practical investigation is not only to increase conversion and selectivity, but also to decrease the temperature of the process, making the reaction more localized and thus decreasing diffusion of half-products, which might be unselectively oxidized. Here, a spin catalyst, which is able to prevent recombination of broken $\mathrm{C}-\mathrm{H}$ bonds and activate $\mathrm{O}_{2}$ to the singlet state (or allow its easy dissociation), might be useful.

\subsection{Cyclization}

Transformation to a biradical state is both necessary and sufficient in a lot of cyclization reactions (e.g., anti-Hückel cycloaddition) [29]. A spin catalyst might increase the rate of the reaction by enhancing transformations between different spin states of such biradicals. Another example is cyclization of $n$-hexane to $c$-hexane, which occurs through cleavage of primary $\mathrm{C}-\mathrm{H}$ bonds. It is known that geometrical prearrangement on the surface of the catalyst increases the selectivity of this cyclization. However, there is still not an effective catalyst for selective cleavage of these $\mathrm{C}-\mathrm{H}$ bonds, which can be achieved by geometrically placing the ends of the $n$-hexane close to the spin center.

\subsection{Cycle opening}

In contrast to cyclization, change of the spin state might be

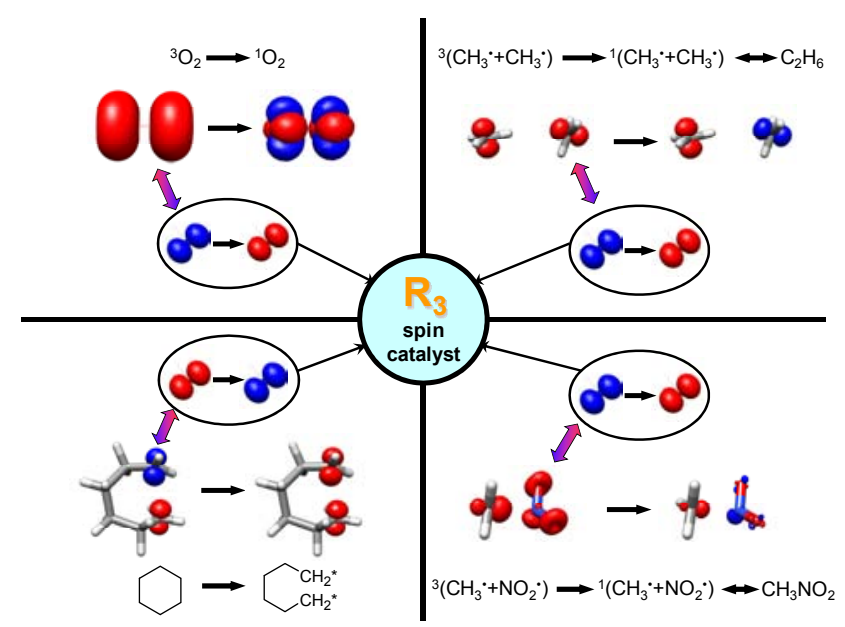

Fig. 3. Examples of spin-catalyzed processes: activation of $\mathrm{O}_{2}$ (top left), coupling of methyl radical (top right), $c$-hexane cycle opening (bottom left), and coupling of nitromethane (bottom right). Positive and negative spin densities are denoted with red and blue clouds, respectively. crucial for cycle opening (Fig. 3, bottom left). For instance, in the synthesis of maleic anhydride from benzene or phtalic anhydride, the naphthalene $\mathrm{C}=\mathrm{C}$ bond is cleaved via cycloaddition of $\mathrm{O}_{2}$, which requires transition to the singlet state so can be promoted by spin catalysis.

\subsection{Activation of small non-polar molecules}

Molecules like $\mathrm{H}_{2}$ or $\mathrm{Cl}_{2}$ are difficult to activate using standard acid-base catalysts because of their zero dipole moment and low polarizability. However, spin catalysts, which are able to induce spin changes, might enable their transition to the active triplet state or lead to their homolytic dissociation. The radicals evolved can either initiate chain reactions or donate/accept an electron, transforming into reactive ions. These properties are widely exploited in the water-gas shift reaction and synthesis of phosgene.

\section{6. $\quad$ Coupling of unstable radicals}

Nitromethane $\left(\mathrm{CH}_{3} \mathrm{NO}_{2}\right)$, a monopropellant, can be formed by coupling $\mathrm{CH}_{3} \cdot$ and $\mathrm{NO}_{2} \cdot$ radicals (Fig. 3, top and bottom right) [30]. However, the temperature of this process should be low to prevent chain decomposition of the compound. A spin catalyst might increase the rate of the coupling reaction at low temperatures by increasing the partition of singlet pairs formed upon collision of radicals.

\section{Possible candidates for spin catalysts}

Finally, we will give possible candidates for spin catalysts. First, magnetic oxides and polynuclear magnetic clusters containing different paramagnetic metal ions, e.g., Mn(II/III/V), Fe(III), Co(II), and Cu(II) [10-14, 31-35]. Second, polynuclear complexes of transition metals (in low-temperature catalysis) grafted on supports [14]. Third, materials with non-integer oxidative states of metals (e.g., bronzes) that are also conductive [36]. Finally, different types of carbon materials that possess half-metallicity, i.e., equal stability of several multiplicity states [37], and are good conductors (e.g., B- or N-doped carbon particles, where partially localized spins should be observed $[38,39])$.

\section{Concluding remarks}

There is one significant problem with investigation of spin-catalyzed reactions: most of these processes are of radical nature, and thus tend to fall into the non-linear regime, which makes them difficult to predict. The physics (and mathematical background) of non-linear processes is still unclear, so there is not a convenient tool to describe and, more importantly, predict a cascade of spin-catalyzed reactions. However, the merits of such studies might be as good as unexpected. As well as the ordinary tuning the reactions (e.g., low-temperature selective oxidation or metal-free catalysis), a unique tool to non-thermodynamically control reactions could be developed, with elementary processes being triggered by an external elec- 
tric or magnetic field. This would have clear advantages in control over reactor media, which is now mainly achieved by changing the temperature, pressure, and flow rates (parameters with a long delay of response). Change of reaction rates by an external magnetic field would allow immediate response of the system, which is much preferable. Additionally, fine control over elementary reactions opens a way to suppress undesirable by-processes through decrease of the temperature, and thus makes them less stochastic.

\section{References}

[1] Minaev B F, Ågren H. Int J Quantum Chem, 1998, 57: 519

[2] Buchachenko A L, Berdinsky V L. Chem Rev, 2002, 102: 603

[3] Buchachenko A L, Berdinsky V L. Russ Chem Rev, 2004, 73: 1033

[4] Schwarz H. Int J Mass Spectr, 2004, 237: 75

[5] Schröder D, Schwarz H. Reactivity Concepts for Oxidation Catalysis: Spin and Stoichiometry Problems in Dioxygen Activation. In: Quinkert G, Kisakürek M V Eds. Essays in Contemporary Chemistry: From Molecular Structure towards Biology. New York: Wiley-VCH, 2007. 131

[6] Salikhov K M, Molin Yu N, Sagdeev R Z, Buchachenko A L. Spin Polarization and Magnetic Effects in Radical Reactions. Budapest: Akademiai Kiado, 1984. 419

[7] Turro N J, Arora K S. Macromolecules, 1986, 19: 42

[8] Wang J F, Welsh K M, Waterman K C, Fehiner P, Doubleday C Jr, Turro N J.J Phys Chem, 1988, 92: 3730

[9] Sakaguchi Y, Hayashi H. Chem Phys, 1992, 162: 119

[10] Yamaguchi K, Shoji M, Isobe H, Kitagawa Y, Yamada S, Kawakami T, Yamanaka S, Okumura M. Polyhedron, 2013, 66: 228

[11] Prabhakar R, Siegbahn P E M, Minaev B F, Ågren H. J Phys Chem B, 2004, 108: 13882

[12] Himo F, Siegbahn P E M. Chem Rev, 2003, 103: 2421

[13] Minaev B F, Murugan N A, Ågren H. Int J Quantum Chem, 2013, 113: 1847

[14] Yamanaka S, Saito T, Kanda K, Isobe H, Umena Y, Kawakami K, Shen J R, Kamiya N, Okumura M, Nakamura H, Yamaguchi K. Int J Quantum Chem, 2012, 112: 321

[15] Stass D V, Woodward J R, Timmel C R, Hore P J, McLauchlan K A. Chem Phys Lett, 2000, 329: 15
[16] Turro N J.J Org Chem, 2011, 76: 9863

[17] Terenzi C, Bouguet-Bonnet S, Canet D. J Phys Chem Lett, 2015, 6: 1611

[18] Mori Y, Sakaguchi Y, Hayashi H.J Phys Chem A, 2002, 106: 4453

[19] Mi Q, Chernick E T, McCamant D W, Weiss E A, Ratner M A, Wasielewski M R. J Phys Chem A, 2006, 110: 7323

[20] Cohen A E. J Phys Chem A, 2009, 113: 11084

[21] Isobe H, Yamanaka S, Kuramitsu S, Yamaguchi K. J Am Chem Soc, 2008, 130: 132

[22] Maeyama T, Matsui H, Yago T, Wakasa M. J Phys Chem C, 2010, 114: 22190

[23] Okazaki M, Toriyama K, Oda K, Kasai T. Phys Chem Chem Phys, 2002, 4: 1201

[24] Okazaki M, Tanimoto Y, Konishi Y, Toriyama K. J Phys Chem, 1996, 100: 9403

[25] Khavryuchenko O V, Frank B, Trunschke A, Hermann K, Schlögl R. J Phys Chem C, 2013, 117: 6225

[26] Rodgers C T. Pure Appl Chem, 2009, 81: 19

[27] Schweitzer C, Schmidt R. Chem Rev, 2003, 103: 1685

[28] Baik M H, Newcomb M, Friesner R A, Lippard S J. Chem Rev, 2003, 103: 2385

[29] Cloonan M 0. Int J Hydrogen Energy, 2007, 32: 159

[30] Markofsky S B. Nitro Compounds, Aliphatic. Ullmann's Encyclopedia of Industrial Chemistry. Weinheim: Wiley-VCH, 2000. 291

[31] Minaev B F. J Mol Catal A, 2001, 171: 53

[32] Pietrzyk P, Zasada F, Piskorz W, Kotarba A, Sojka Z. Catal Today, 2007, 119: 219

[33] Kruczała K, Szczubiałka K, Łańcucki Ł, Zastawny I, Góra-Marek K, Dyrek K, Sojka Z. Spectrochim Acta A, 2008, 69: 1337

[34] Spier E, Neuenschwander U, Hermans I. Angew Chem Int Edt, 2013, 52: 1581

[35] Busch M, Ahlberg E, Panas I. Phys Chem Chem Phys, 2011, 13: 15062

[36] Khavryuchenko O V, Stus N V, Peslherbe G H. Solid State Commun, 2012, 152: 2138

[37] Khavryuchenko O V, Khavryuchenko V D, Lisnyak V V, Peslherbe G H. Chem Phys Lett, 2011, 513: 261

[38] Schlögl R. Adv Catal, 2013, 56: 103

[39] Arrigo R, Schuster M E, Xie Z, Yi Y, Wowsnick G, Sun L L, Hermann K E, Friedrich M, Kast P, Hävecker M, Knop-Gericke A, Schlögl R. ACS Catal, 2015, 5: 2740

\section{Graphical Abstract}

Chin. J. Catal., 2015, 36: 1656-1661 doi: 10.1016/S1872-2067(15)60948-2

\section{Spin catalysts: A quantum trigger for chemical reactions}

Oleksiy V. Khavryuchenko*, Volodymyr D. Khavryuchenko, Dangsheng Su * Computation Chemistry Group, Ukraine;

Institute of Metal Research, Chinese Academy of Science, China;

Fritz Haber Institute of the Max Planck Society, Germany

Solid spin-conductive catalysts can transfer spin moment sign and, thus, facilitate covalent bond cleavage, radicals coupling or activation of reactants to electron excited state within the spin catalysis paradigm.

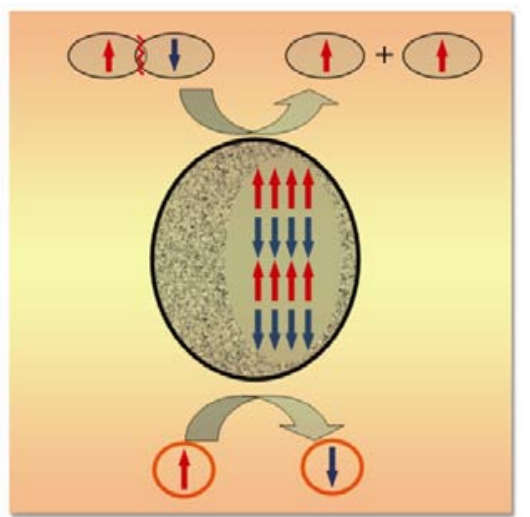




\title{
自旋催化剂一量子触发化学反应
}

\author{
Oleksiy V. Khavryuchenko ${ }^{\mathrm{a}, \#}$, Volodymyr D. Khavryuchenko ${ }^{\mathrm{a}}$ ，苏党生 ${ }^{\mathrm{b}, \mathrm{c}, *}$ \\ a计算化学集团, 乌克兰基辅UA-02091

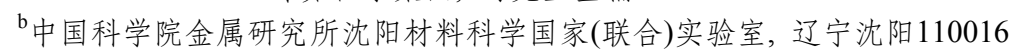 \\ `马克斯普朗克协会弗里茨·哈伯研究所无机化学系, 德国柏林Faradayweg 4-6, D-14195
}

\begin{abstract}
摘要: 当初始态和过渡态之间存在能量差时, 通常会考虑用催化的方法来增加反应速率, 即经由能量更低过渡态的反应路径, 或 增加反应物初始态能量, 如改变溶剂或在特殊表面吸附分子. 然而, 对于某些类型的反应, 如 $\mathrm{H}_{2}$ 和 $\mathrm{O}_{2}$ 反应生成水, $\mathrm{NO}$ 的氧化等, 仅 仅采用这些方法还不够, 因为反应物和产物具有不同的自旋态, 而自旋守恒定律一般会禁止该过程的发生. 即使克服了能垒, 该 体系也不能转化成稳定的产物, 且不改变其电子自旋多重态. 但在特殊的非热力学条件下, 该类反应仍可发生. 这通常指自旋不 守恒的过程. 改变体系电子自旋最直接的方法是与原子核自旋有作用的电子自旋翻转. 它可由自旋-轨道耦合来实现, 因此, 其实 现的几率取决于元素的原子数. 从 $3 d$ 金属开始, 发生这种情况的可能性甚至更大. 这是由于与 $d$ 轨道耦合的效率更高所致, 所以采 用自旋交叉就能方便地解释自旋禁止反应发生的原因. 然而, 轻原子发生自旋翻转的可能性很低, 因此, 当面对无金属化学时, 我 们应该考虑自旋禁止反应发生的第二个方法一自旋催化.

通过帮助克服自旋禁止的物质以促进化学反应, 或通过顺磁催化剂诱导自旋解耦以降低活化能垒, 这类现象就可定义为自旋 催化. 简而言之, 为了得到想要的和热力学更有利的自旋态, 一个反应粒子可以与自旋催化剂交换磁矩; 该自旋催化剂需有拟自 旋-简并基态或低激发态. 因此, 体系整个的自旋仍守恒, 但可发生反应. 值得强调的是, 自旋“催化剂”指的是分子状态和固体状 态, 通常后者应用于工业中则方便得多.

自旋催化是作为自旋化学的范例来研究的, 或在外磁场中化学诱导动态核极化和反应, 主要是指采用EPR光谱研究以液相为 主的过程. 本文简略介绍了自旋催化的理论. 实际上, 自旋催化与常规催化之间并不相互抵触一相同的材料既可作为自旋催化 剂, 也可用作常规催化剂, 都起着降低反应能垒和提供自旋交换的自由基中心的作用. 另外, 许多现代材料包含着常规催化剂和 自旋催化剂的特性. 有些发生在多核磁性金属中心上的过程可能本身就包含着常规催化(活化底物)、自旋交叉(与 $d$ 金属相互作用) 和自旋催化(金属-氧簇合物中低能的铁磁-反铁磁转化)效应.

气相自旋催化在实际应用中产生的主要问题是在稀释的体系中三粒子碰撞几率低, 常规催化在这方面则有很多优势. 我们 首先列出固体成为自旋催化剂的条件: (1)活性中心中至少 2 个自旋态的能量差要小于反应温度下热运动的能量, 这样无需额外的 能量活化催化剂; (2)较大的比表面积以提供更多的自旋中心用于相互作用; (3)最好能够自旋导电, 在此情况下反应无需三粒子 碰撞即可发生. 这是因为自由基可通过催化剂的电子系统交换自旋, 使得自旋-自旋相互作用的几率迅速增加, 从而有利于自旋催 化反应的进行. 另外, 如果固体或载体具有自旋导电性, 则无需外加电场或磁场, 即有可能遥控催化中心的电荷和自旋态, 从而避 免使用外电场或磁场.
\end{abstract}

实际上, 许多反应过程本身就包含着自旋催化, 它还可使反应过程的许多不足变成优势, 如对于不需要的链式自由基反应; 通过引入自旋捕获剂使得自旋禁止反应成为有用的自旋催化; 磁性粒子的浓度以及外加磁场和电场均可导致自旋催化/禁止反 应. 由于均相自旋催化的研究较早, 在此不再赘述. 本文详细介绍了多相体系中的自旋催化的应用, 如燃烧、温和氧化、环化、开 环、非极性小分子的活化和不稳定自由基的耦合等.

可能用作自旋催化剂的材料有: 含有不同顺磁性的金属离子的磁性氧化物或多核磁性簇合物; 嫁接在一些载体上的多核络 合物或过渡金属(低温催化); 带有非整数氧化价态的导电金属; 各种具有半金属性和导电性的碳材料. 研究自旋催化反应的一个 突出问题就是这些过程大部分是自由基式的, 趋于非线性区域, 因而很难预测, 也没有一个便利的工具用以描述, 甚至预测自旋催 化反应, 但也许这些研究的特点就是不可预测性. 自旋催化除了可调变反应的进行, 我们还可从中获得一个独特的调节手段: 通 过外加磁场或电场触发基元过程, 在非热力学上控制反应的进行. 该手段在控制化学反应方面具有明显优势, 因为现在大都是通 过调节温度、压力和流量等参数来实现对化学反应的控制, 且滞后严重. 同时, 通过添加外加磁场可立刻改变反应速率. 另外, 通 过降温可精细控制基元反应, 从而开辟了一种抑制副反应的方法, 因而也使得反应的随机性降低.

关键词: 催化; 自旋化学; 化学键均裂; 氧化过程; 自由基耦合

收稿日期: 2015-04-15. 接受日期: 2015-06-28. 出版日期: 2015-10-20.

*通讯联系人. 电话: (024)23971577; 传真: (024)83970019; 电子信箱: dssu@imr.ac.cn

\#通讯联系人. 电话: +38-044-5637135; 传真: +38-044-5634274; 电子信箱: alexkhavr@gmail.com

本文的英文电子版由Elsevier出版社在ScienceDirect上出版(http://www.sciencedirect.com/science/journal/18722067). 